\title{
Cultural competence in mental health nursing: validity and internal consistency of the Portuguese version of the multicultural mental health awareness scale-MMHAS
}

\author{
Ana Paula Teixeira de Almeida Vieira Monteiro ${ }^{1 *}$ and Alexandre Bastos Fernandes ${ }^{2}$
}

\begin{abstract}
Background: Cultural competence is an essential component in rendering effective and culturally responsive services to culturally and ethnically diverse clients. Still, great difficulty exists in assessing the cultural competence of mental health nurses. There are no Portuguese validated measurement instruments to assess cultural competence in mental health nurses. This paper reports a study testing the reliability and validity of the Portuguese version of the Multicultural Mental Health Awareness Scale-MMHAS in a sample of Portuguese nurses.

Methods: Following a standard forward/backward translation into Portuguese, the adapted version of MMHAS, along with a sociodemographic questionnaire, were applied to a sample of 306 Portuguese nurses (299 males, 77 females; ages 21-68 years, $M=35.43, S D=9.85$ years). A psychometric research design was used with content and construct validity and reliability. Reliability was assessed using internal consistency and item-total correlations. Construct validity was determined using factor analysis.

Results: The factor analysis confirmed that the Portuguese version of MMHAS has a three-factor structure of multicultural competencies (Awareness, Knowledge, and Skills) explaining $59.51 \%$ of the total variance. Strong content validity and reliability correlations were demonstrated. The Portuguese version of MMHAS has a strong internal consistency, with a Cronbach's alpha of 0.958 for the total scale.

Conclusions: The results supported the construct validity and reliability of the Portuguese version of MMHAS, proving that is a reliable and valid measure of multicultural counselling competencies in mental health nursing. The MMHAS Portuguese version can be used to evaluate the effectiveness of multicultural competency training programs in Portuguese-speaking mental health nurses. The scale can also be a useful in future studies of multicultural competencies in Portuguese-speaking nurses.
\end{abstract}

Keywords: Mental Health Nurses, Multicultural awareness, Multicultural nursing, Cultural competence, Psychometric testing, Instrument validity, Instrument reliability

\footnotetext{
* Correspondence: anapaula@esenfc.pt

Validity and internal consistency of the Portuguese version of the

Multicultural Mental Health Awareness Scale-MMHAS

'Coimbra Nursing School, Rua 5 de Outubro-Apartado 55, 3001-901 Coimbra,

Portugal

Full list of author information is available at the end of the article
} 


\section{Background}

The role of migration in European population change is being debated during recent years as a result of growing concerns about issues such as demographic ageing, shortages of working age populations and payment of pensions among others [1]. In 2015, Europe is suffering from the worst refugee crises since World War II. These refugees are fleeing war, violence and persecution in their country of origin.

Immigrants and asylum-seekers have a higher risk of mental illness due to the fact that they often have been exposed to extreme conditions-for instance, forced migration, significant personal losses and other human rights violations-simply due to the fact that they are refugees in a foreign country, with different cultural norms [2].

Mental health issues including major depression disorder, post-traumatic stress disorder, and general anxiety disorder are common among newly arrived immigrants and refugees. While many immigrants and refugees are resilient, traumatic experiences and migration stressors have a great impact on their mental well-being [3-5].

As the largest group of health professionals in the world, nurses are the key to providing cost effective mental health care to this vulnerable populations, meeting the immigrants and refugees' complex mental health needs. Nurses are key to healthcare for refugees and migrants [6]. However, most nurses lack competence and confidence in dealing with the distress and mental health problems of refugees and migrants. Lack of cultural competence in mental health among nurses limits the potential to provide high-quality care for the growing number of people with diverse backgrounds [7]. An additional factor that can be a conundrum when examining standards for culturally competent mental health care is the lack of uniformity in educating mental health providers about cultural competence and inconsistencies in how cultural competence is defined [8].

Cultural competence can be seen as a necessary set of skills for mental health nurses to attain in order to render effective patient-centred care. Still, there is limited literature available identifying and describing the instruments that measure mental cultural competence in nursing professionals. These instruments are crucial to assess their cross-cultural strengths and weaknesses in order to design specific training activities or interventions that promote multicultural competence in mental health care [9].

Portuguese is the world's sixth most spoken language (in America, Africa and Europe there are over 230 million Portuguese speakers) and millions of nurses are using Portuguese as the first language in health care. In spite of this fact, there are no Portuguese validated measurement instruments to assess cultural competence in mental health among nurses.
Cultural competency has been defined as a set of congruent behaviors, attitudes and policies that come together in a system, agency or among professionals that enable that system, agency or those professions to work effectively in cross-cultural situations. It has been seen as the ongoing process in which the health care provider continuously strives to work effectively within the cultural context of the client [10]. Thus, cultural competence is active, developmental, and is aspirational rather than achieved [11].

The tripartite cultural competence model [12, 13] has three components: 1-Cultural awareness, 2-Cultural knowledge, and 3-Cultural skills. First, the awareness component refers to the mental health professional's awareness of one's own worldview and cultural biases. Cultural awareness is the self-examination and in-depth exploration of one's own cultural and professional background. In other words, this process involves the recognition of one's biases, prejudices, and assumptions about individuals who are different. A culturally competent professional is one who is actively in the process of becoming aware of his or her own assumptions about human behavior, values, biases, preconceived notions, and personal limitations. Second, cultural knowledge is the process of seeking and obtaining a sound educational foundation about diverse cultural and ethnic groups. In order to obtaining this knowledge base, the health care provider must focus on the integration of three specific issues: health-related beliefs and cultural values, disease incidence and prevalence, and treatment efficacy [14]. A Multicultural knowledge requires mental health givers to be knowledgeable about various cultural factors that might influence the therapeutic process. A culturally competent professional is one who actively attempts to understand the worldview of culturally diverse populations-values, assumptions, practices, communication styles, group norms, biases, and personal experiences.

Multicultural competence of mental health practitioners includes the specific skill of adapting treatments and practices to better match the particular needs of the client [15].

The ethnic composition Portuguese population is becoming increasingly diverse in the last two decades. The Portuguese mental health care system is struggling to address some of the specific challenges presented by recent immigration from Africa, Brazil, Eastern Europe and China [16]. For mental health care providers and specifically nurses, the need to provide culturally appropriate and competent care is recognized as essential. Still, little attention has been given to the development of multicultural competencies among Portuguese health care professionals in mental health settings [17,18]. A study with 22 Portuguese nurses, aiming to analyse personal experiences and significant situations of nursing 
care in multicultural contexts, highlights key multicultural issues that are important for mental health and psychiatric nursing care: therapeutic environment management, roles, speech patterns, and therapeutic communication with minority clients and families [19]. Currently, the instruments to assess cultural competence in nurses and nursing students are self-administered and based on individuals' own perceptions. The instruments are commonly utilized to test the effectiveness of educational programs designed to increase cultural competence [20]. Therefore, instruments that accurately and reliably measure the knowledge, attitudes, and skills reflecting cultural competence in Portuguese mental health nurses are scarce.

A study was developed to evaluate the cultural diversity competence of Portuguese child care workers $(\mathrm{N}=51)$ [21]. The variables integrated a self-report measure- a cultural competence questionnaire, and an objective measure for evaluation of cultural diversity competencies. But this self-report measure had some limitations, namely the small size of the sample in the validation study, the low Alpha Cronbach's in two subscales and the fact that it was targeted to child care workers.

\section{Methods}

\section{Aim}

The aim of this study was to translate and test the psychometric properties of the Portuguese version of the Multicultural Mental Health Awareness Scale-MMHAS.

\section{Design}

A psychometric research design was used with content and construct validity and reliability. Reliability was determined with Cronbach's alpha coefficient.

\section{Sample/participants}

A convenience sample of Registered Nurses (RN) was recruited online using the LimeService/ LimeSurvey hosting platform. The research questionnaire was made available online, and participants were invited to participate by email, social networks, and trough professional contacts. The survey took approximately 20 to $30 \mathrm{~min}$ to complete and was accessed with a link to LimeService/ LimeSurvey hosting platform. The sample is composed of 306 subjects - aged between 21 and 68 years (with an average age of 35.4 years and a standard deviation of 9.8 years); $25.2 \%$ female and $74.8 \%$ male, who agreed to participate in the study and matched the following inclusion criteria: to be a $\mathrm{RN}$ in Portugal and proficiency in Portuguese Language.

\section{Data collection}

Data were collected using the Portuguese version of the Multicultural Mental Health Awareness Scale-MMHAS, along with a socio-demographic questionnaire.

\section{Multicultural mental health awareness scale-MMHAS}

The original Multicultural Mental Health Awareness Scale (MMHAS) was designed to provide a psychometrically sound instrument to successfully assess professional multicultural competence in mental health and the effectiveness of a multicultural training program in mental health. Items on the new scale were generated in order parallel the Queensland Transcultural Mental Health Centre (QTMHC) training program's objectives. Results indicated a scale with 35 items and three factors with moderate to high factor loadings and satisfactory psychometric properties. The three factors found to be interrelated were: Multicultural Counselling Awareness, Multicultural Counselling Knowledge, and Multicultural Counselling Skills, in line with the multicultural counselling competencies. The Cronbach's alpha for the total scale was .91. The internal consistency of the Multicultural Counselling Awareness subscales was .89, .92 for the Multicultural Counselling Knowledge subscale, and .90 for the Skills subscale. The MMHAS is unique as it not only reflects language issues and correct intervention strategies, but also assesses the ability to address service barriers and to work with interpreters [22].

\section{Procedures}

The questionnaire was translated using the back translation system by two bilingual translators. After the translations process, a committee including one expert in mental health, one expert in English Language and Literature, also bilingual and, the researcher discussed discrepancies and agreed upon an integrated version of the translation. A group of nursing students reviewed the questionnaire with the investigator to check the appropriateness of the translations and resolved remaining discrepancies in translations. Consensus in terms of semantic, idiomatic, experiential, and conceptual equivalence was reached and a final version of the MMHAS Portuguese version was provided. The study sample was identified using a convenience sampling method. After a process of translation and transcultural validation, the Portuguese version of MMHAS, along with a socio-demographic questionnaire, were applied to a sample of 306 Portuguese nurses. The research questionnaire was made available online, and participants were invited to participate by email, social networks, and trough professional contacts. The information of the study was disseminated online in several nursing professional networks and social network sites (Facebook, Portuguese Nursing Blogs; Portuguese 
Nursing sites). Only a few participants were directed notified, for ex. with a personnel email with a link.

The survey took approximately 20 to $30 \mathrm{~min}$ to complete and was accessed with a link to LimeService/ LimeSurvey hosting platform. LimeSurvey provides a web-based product for internet surveys with more than twenty different question formats, in addition to survey tokens that prevent repeat participants, and branching surveys that offer different questions depending on prior responses. Moreover, the survey administrator can control how the survey interface will appear to participants through a built-in editor. Surveys were available online from November 2013 to February 2014. Once the recruitment period had ended all data was condensed into a file, downloaded into a database, exported into SPSS and, statistical analysis was conducted. It was not possible to determinate a response rate.

\section{Ethical considerations}

Internet data collection can raise particular, sometimes non-obvious challenges in adhering to ethical principles. In this study we followed the Ethics Guidelines for Internet Mediated Research [23] and the American Psychological Association's Guidelines [24]. Study inclusion required informed consent. Participants were informed that they could withdraw from the study at any time. Regarding ethical aspects in research, it is worth highlighting that authorization to make cultural adaptation and validation of the MMHA for the Portuguese reality was obtained from the author of the original instrument. The study was formally approved by the Ethical Committee for Health Research of Coimbra Nursing School.

\section{Data analysis}

Data analyses were completed with the use of Statistical Package for the Social Sciences version 20.0 (SPSS, Chicago, IL, USA). To explore the MMHAS internal consistency, Cronbach's alpha was obtained, as well as item-total correlations and alpha values when the item was deleted. Exploratory factor analysis (principal component analysis) was carried out to identify factor structure of MMHAS (Portuguese version).

\section{Results}

\section{Participants}

The sample was composed of 306 subjects-aged between 21 and 68 years, with an average age of 35.43 years and a standard deviation of 9.85 years; 299 males (74.8 \%) and 77 females (25.2\%).

Demographic characteristics of the respondents are summarized in Table 1.
Table 1 Sociodemographic characterization of the sample

\begin{tabular}{|c|c|c|}
\hline & Number & Percent \\
\hline \multicolumn{3}{|l|}{ Age range } \\
\hline $\begin{array}{l}{[20-30[} \\
{[30-40[} \\
{[40-50[} \\
{[50-60[} \\
{[60-70]}\end{array}$ & $\begin{array}{l}104 \\
101 \\
72 \\
26 \\
3\end{array}$ & $\begin{array}{l}34.0 \\
33.0 \\
23.5 \\
8.5 \\
1.0\end{array}$ \\
\hline $\begin{array}{l}\bar{x}=35.43 ; M d=33.00 ; s=9.85 ; x_{\min }=21.00 \\
x_{\operatorname{máx}}=68.00 ;\end{array}$ & $p=0.000$ & \\
\hline \multicolumn{3}{|l|}{ Gender } \\
\hline $\begin{array}{l}\text { Female } \\
\text { Male }\end{array}$ & $\begin{array}{l}77 \\
229\end{array}$ & $\begin{array}{l}25.2 \\
74.8\end{array}$ \\
\hline \multicolumn{3}{|l|}{ Marital status } \\
\hline $\begin{array}{l}\text { Single } \\
\text { Married } \\
\text { Divorced/Separated } \\
\text { Widowed } \\
\text { Civil Union }\end{array}$ & $\begin{array}{l}133 \\
127 \\
14 \\
3 \\
29\end{array}$ & $\begin{array}{l}43.5 \\
41.5 \\
4.6 \\
1.0 \\
9.5\end{array}$ \\
\hline \multicolumn{3}{|l|}{ Profissional status } \\
\hline $\begin{array}{l}\text { RN } \\
\text { Graduated Nurse } \\
\text { Specialized Nurse } \\
\text { Unemployed }\end{array}$ & $\begin{array}{l}300 \\
1 \\
4 \\
1\end{array}$ & $\begin{array}{l}98.0 \\
0.3 \\
1.3 \\
0.3\end{array}$ \\
\hline \multicolumn{3}{|l|}{ Professional experience (years) } \\
\hline $\begin{array}{l}<5 \\
{[5-10[} \\
{[10-15[} \\
{[15-20[} \\
{[20-25[} \\
{[25-30[} \\
{[30-35[} \\
\geq 35\end{array}$ & $\begin{array}{l}82 \\
67 \\
46 \\
27 \\
37 \\
26 \\
14 \\
4\end{array}$ & $\begin{array}{l}26.8 \\
21.9 \\
15.0 \\
8.8 \\
12.1 \\
8.5 \\
4.6 \\
1.3\end{array}$ \\
\hline \multicolumn{2}{|c|}{$\bar{x}=12.23 ; M d=10.00 ; s=9.79 ; x_{\min }=0.00 ; x_{\operatorname{máx}}=42.00 ;$} & $p=0.000$ \\
\hline
\end{tabular}

\section{Principal component analysis}

In our exploratory factor analysis, the Kaiser Mayer Olkin Measure and the Bartlett's chi square tests were checked for the appropriateness of data for factor analysis. Both the adequacy of the sample and the use of factor analysis on the data were confirmed.

The Kaiser-Meyer-Olkin (KMO) measure of sampling adequacy was 0.949 , exceeding the benchmark value of 0.60 . The Bartlett's Test of Spehericity $\left(\chi^{2}=\right.$ $7776.696 ; \mathrm{p}=0.000)$ was statistically significant, supporting the factorability of the correlation matrix. A principal component analysis (PCA) with orthogonal varimax rotation and combined scree plot test and parallel analysis yielded a three factor solution that accounted for $59.4 \%$ of the total variance explained (Table 2). A principal component analysis (PCA) with orthogonal varimax procedure was employed to rotate the factors to a simple structure in order to determine the number of factors to retain. Items with a loading of greater than 0.50 were retained for a specific factor. Split items were retained to factors if the 
Table 2 Loadings (item-component correlations) obtained by PCA

\begin{tabular}{|c|c|c|c|}
\hline \multirow[t]{2}{*}{ Item } & \multicolumn{3}{|l|}{ Factors } \\
\hline & $\overline{\mathrm{C} 1}$ & C2 & C3 \\
\hline 1. & 0.147 & 0.508 & 0.222 \\
\hline 2. & 0.278 & 0.602 & 0.191 \\
\hline 3. & 0.214 & 0.703 & 0.199 \\
\hline 4. & 0.128 & 0.810 & 0.093 \\
\hline 5. & 0.192 & 0.749 & 0.164 \\
\hline 6. & 0.174 & 0.792 & 0.188 \\
\hline 7. & 0.221 & 0.626 & 0.346 \\
\hline 8. & 0.148 & 0.782 & 0.182 \\
\hline 9. & 0.143 & 0.810 & 0.183 \\
\hline 10. & 0.047 & 0.788 & 0.262 \\
\hline 11. & 0.101 & 0.625 & 0.362 \\
\hline 12. & 0.614 & 0.246 & 0.062 \\
\hline 13. & 0.715 & 0.224 & 0.147 \\
\hline 14. & 0.842 & 0.152 & 0.141 \\
\hline 15. & 0.840 & 0.130 & 0.168 \\
\hline 16. & 0.746 & 0.111 & 0.251 \\
\hline 17. & 0.584 & 0.300 & 0.261 \\
\hline 18. & 0.731 & 0.136 & 0.304 \\
\hline 19. & 0.743 & 0.095 & 0.281 \\
\hline 20. & 0.767 & 0.137 & 0.273 \\
\hline 21. & 0.648 & 0.154 & 0.252 \\
\hline 22. & 0.509 & 0.283 & 0.397 \\
\hline 23. & 0.544 & 0.260 & 0.356 \\
\hline 24. & 0.659 & 0.090 & 0.316 \\
\hline 25. & 0.273 & 0.050 & 0.551 \\
\hline 26. & 0.302 & 0.089 & 0.541 \\
\hline 27. & 0.287 & 0.222 & 0.707 \\
\hline 28. & 0.241 & 0.221 & 0.751 \\
\hline 29. & 0.346 & 0.271 & 0.711 \\
\hline 30. & 0.225 & 0.281 & 0.765 \\
\hline 31. & 0.181 & 0.349 & 0.747 \\
\hline 32. & 0.332 & 0.213 & 0.692 \\
\hline 33. & 0.159 & 0.263 & 0.748 \\
\hline 34. & 0.189 & 0.276 & 0.667 \\
\hline 35. & 0.104 & 0.289 & 0.519 \\
\hline Value & 14.8 & 3.7 & 2.3 \\
\hline Explained variance. (\%) & 42.3 & 10.5 & 6.6 \\
\hline
\end{tabular}

Rotation Method: Varimax with Kaiser Normalization

Extraction Method: Principal Component Analysis

square of the loadings for a factor was $>50 \%$ that of its loading on any other factor (Table 2).

The items of the MMHAS Portuguese version total scale can be divided into three subscales:
Factor 1-Cultural Awareness, with thirteen items (12, 13, 14, 15, 16, 17, 18, 19, 20, 21, 22, 23 and 24).

Factor 2-Cultural Knowledge, with eleven items (1, 2, 3, 4, 5, 6, 7, 8, 9, 10 and 11).

Factor 3-Cultural Competence/Skills, with eleven items (25, 26, 27, 28, 29, 30, 31, 32, 33, 34 and 35).

As can be seen from Table 2, all the items (except item 1 and item 2) load onto their original subscales with loading values of .90 or greater in each case. The Item 1 "My knowledge of various cultures is" in the original questionnaire, and in the Portuguese version "o meu conhecimento sobre outras culturas é"-in the original study of the MMHA loaded in the Factor 1 (Cultural Awareness) and in the Portuguese version loaded in the Factor 2 (Cultural Knowledge). Also the Item 2-"My knowledge of acculturation is" in the original questionnaire, and in the Portuguese version "O meu conhecimento sobre o processo de aculturação é"-in the original study of the MMHA loaded in the Factor 1 (Cultural Awareness) and in the Portuguese version loaded in the Factor 2 (Cultural Knowledge). The variations can be explained by some cultural, semantic and linguistic differences between the Portuguese and English versions. The mean inter-item correlations, which can be regarded as an indicator of the homogeneity of the scale, were also computed. In the sample, the mean inter item correlations are rather high.

\section{Internal consistency reliability}

The overall reliability coefficient Cronbach's alpha, is based on the average correlation of items within the scale. Cronbach's alpha coefficient of reliability of the MMHAS Portuguese version is 0.958 . For the subscale Multicultural Awareness Cronbach's alpha is 0.938; for the subscale Multicultural Knowledge Cronbach's alpha is 0.927 and, for the subscale Multicultural Competence/ Skills Cronbach's alpha is 0.922 (Table 3).

The extent to which individual items affect the reliability of the scale can be examined by calculating Cronbach's alpha when each item is removed from the scale. The removal of any single item would not significantly increase the reliability of the scale: in all the items of the scale where the alpha if deleted isn't higher than the overall alpha and in subscales (Table 3).

\section{Discussion}

Cultural competence is an essential component in rendering effective and culturally responsive services to culturally and ethnically diverse clients [25]. Because providing culturally competent care is essential in nursing, the measurement of cultural competence and its effect on patient outcomes is central to the discipline. Despite the limitations associated with existing instruments, there is much 
Table 3 Reliability Statistics-Cronbach's a coefficients of reliability

\begin{tabular}{|c|c|c|c|c|c|c|c|c|}
\hline \multirow[t]{2}{*}{ Item } & \multicolumn{2}{|c|}{ Awareness } & \multicolumn{2}{|c|}{ Knowledge } & \multicolumn{2}{|l|}{ Skills } & \multicolumn{2}{|c|}{ Total MMHAS } \\
\hline & $\bar{A}$ & $B$ & $\bar{A}$ & $B$ & $\bar{A}$ & $B$ & $\bar{A}$ & $B$ \\
\hline 01 & - & - & 0.524 & 0.928 & - & - & 0.459 & 0.958 \\
\hline 02 & - & - & 0.630 & 0.924 & - & - & 0.572 & 0.957 \\
\hline 03 & - & - & 0.705 & 0.921 & - & - & 0.587 & 0.957 \\
\hline 04 & - & - & 0.756 & 0.918 & - & - & 0.528 & 0.958 \\
\hline 05 & - & - & 0.727 & 0.920 & - & - & 0.578 & 0.957 \\
\hline 06 & - & - & 0.773 & 0.918 & - & - & 0.603 & 0.957 \\
\hline 07 & - & - & 0.673 & 0.923 & - & - & 0.639 & 0.957 \\
\hline 08 & - & - & 0.760 & 0.918 & - & - & 0.579 & 0.957 \\
\hline 09 & - & - & 0.785 & 0.917 & - & - & 0.589 & 0.957 \\
\hline 10 & - & - & 0.767 & 0.918 & - & - & 0.564 & 0.957 \\
\hline 11 & - & - & 0.650 & 0.923 & - & - & 0.570 & 0.957 \\
\hline 12 & 0.571 & 0.938 & - & - & - & - & 0.520 & 0.958 \\
\hline 13 & 0.704 & 0.934 & - & - & - & - & 0.627 & 0.957 \\
\hline 14 & 0.799 & 0.931 & - & - & - & - & 0.665 & 0.957 \\
\hline 15 & 0.798 & 0.931 & - & - & - & - & 0.667 & 0.957 \\
\hline 16 & 0.737 & 0.933 & - & - & - & - & 0.645 & 0.957 \\
\hline 17 & 0.652 & 0.936 & - & - & - & - & 0.649 & 0.957 \\
\hline 18 & 0.757 & 0.932 & - & - & - & - & 0.679 & 0.957 \\
\hline 19 & 0.746 & 0.932 & - & - & - & - & 0.650 & 0.957 \\
\hline 20 & 0.778 & 0.932 & - & - & - & - & 0.688 & 0.957 \\
\hline 21 & 0.663 & 0.935 & - & - & - & - & 0.605 & 0.957 \\
\hline 22 & 0.677 & 0.935 & - & - & - & - & 0.731 & 0.956 \\
\hline 23 & 0.693 & 0.934 & - & - & - & - & 0.717 & 0.956 \\
\hline 24 & 0.688 & 0.934 & - & - & - & - & 0.614 & 0.957 \\
\hline 25 & - & - & - & - & 0.546 & 0.922 & 0.493 & 0.958 \\
\hline 26 & - & - & - & - & 0.577 & 0.920 & 0.526 & 0.958 \\
\hline 27 & - & - & - & - & 0.728 & 0.913 & 0.677 & 0.957 \\
\hline 28 & - & - & - & - & 0.767 & 0.912 & 0.672 & 0.957 \\
\hline 29 & - & - & - & - & 0.789 & 0.911 & 0.744 & 0.956 \\
\hline 30 & - & - & - & - & 0.779 & 0.911 & 0.701 & 0.957 \\
\hline 31 & - & - & - & - & 0.768 & 0.912 & 0.698 & 0.957 \\
\hline 32 & - & - & - & - & 0.740 & 0.913 & 0.692 & 0.957 \\
\hline 33 & - & - & - & - & 0.734 & 0.913 & 0.641 & 0.957 \\
\hline 34 & - & - & - & - & 0.691 & 0.915 & 0.622 & 0.957 \\
\hline 35 & - & - & - & - & 0.523 & 0.925 & 0.491 & 0.958 \\
\hline Cronbach's Alpha & 0.938 & & 0.927 & & 0.922 & & 0.958 & \\
\hline
\end{tabular}

A-Item-total correlation; B-Cronbach's Alpha if item Deleted

value in the initial assessment of cultural competence they provide as well as tracking measurements of cultural competence over time. The aim of the study was to investigate whether the Portuguese version of the MMHAS has satisfactory psychometric properties. The procedures of translation and cultural adaptation represented no major problems and gave rise to a reliable Portuguese version of the MMHAS. PCA was carried out in order to re-examine the factor structure of the scale. The three-factor solution accounted for $54.9 \%$ of the total variance. The items of the MMHAS Portuguese version total scale can be divided into three subscales: Cultural Awareness, Cultural Knowledge, and Cultural Competence/Skills, according the tripartite cultural competence model [26]. Also some 
transcultural nursing models underlies the cultural awareness, cultural knowledge, and cultural skills as crucial components in the process of cultural competence in the delivery of healthcare services.

Excellent Cronbach's alpha coefficients for the three subscales and total scale, and satisfactory item-total coefficients for the correspondent items confirmed that the MMHAS subscales are internally consistent, with the correspondent items properly correlated with each other [27-29]. The results for internal consistency were similar to those obtained by in the original study.

In this study, $74.8 \%$ of the respondents were male, which does not match the sociodemographic composition of Portuguese professional nurses. Some emerging literature points out the correlation between demographic characteristics of subjects and online survey response behavior by investigating how socio-demographic factors, gender in particular, affect online survey response behavior. This is because differences in the way females and males inhabit cyberspace may exaggerate the effects of differences in how females and males undergo social exchange, resulting in differences in online survey response rates [30]. Another explanation is that some of the participants were psychiatric/mental health nurse practitioners, with a considerable number of male nurses.

The MMHAS displayed an apropriate internal consistency. The findings show that the Portuguese version of the MMHAS adequately addressed the original concepts and dimensions, and demonstrated a high level of equivalence with the original version. The findings indicate a remarkable consistency in the factor structure of the Portuguese version. The concepts embedded in this cultural competence questionnaire, provide an ideal structure for educational programs. The Portuguese version of the MMHAS can be used to evaluate the effectiveness of multicultural competency training programs in Portuguese-speaking mental health nurses. The scale can also be a useful in future studies of multicultural competencies in Portuguese nurses.

\section{Limitations}

This study has some limitations including the sample representativeness $(74.8 \%$ male), which does not match the sociodemographic composition of Portuguese professional nurses. Another limitation of this study was the use of a convenience sample, with the inherent bias. Future studies should have larger sample sizes and include gender representative samples, and look at the psychometric performance of the MMHA.

\section{Conclusion}

The results of this study support the construct validity and reliability of the Portuguese version of MMHAS, proving that is a reliable and valid measure of multicultural counselling competencies in mental health. This study suggests that MMHAS could be an important addition to the compendium of instruments used to assess Multicultural Mental Health Competences in Nurses, and also contributes to improve culturally sensitive nursing care.

The MMHAS Portuguese version can be used to evaluate the effectiveness of multicultural competency training programs in Portuguese-speaking mental health nurses. The scale can also be useful in future studies to access multicultural competencies in Portuguese-speaking nurses all around the world.

\section{Ethics and consent to participate}

Study inclusion required informed consent. Participants were informed that they could withdraw from the study at any time. The study was formally approved by the Ethical Committee for Health Research of Coimbra Nursing School-Comissão de Ética da Unidade de Investigação em Ciências da Saúde: Enfermagem da Escola Superior de Enfermagem de Coimbra, Portugal, Committee's reference number:176-072013.

\section{Consent to publish}

Not applicable.

\section{Availability of data and materials}

All the data supporting these findings is contained within the manuscript.

\section{Abbreviations}

MMHAS: Multicultural Mental Health Awareness Scale; PCA: Principal components analysis; QTMHC: Queensland Transcultural Mental Health Centre; RN: Registered Nurses; SPSS: Statistical Package for the Social Sciences.

\section{Competing interests}

The authors declare that they have no competing interests.

\section{Authors' contributions}

Ana Paula Monteiro (APM) and Alexandre Bastos (AB) conceived the study and developed the study material, and conducted the forward and backward translations of the Multicultural Mental Health Awareness Scale-MMHAS. AB carried out data collection. $A B$ conceived and participated in the design of the study and performed the statistical analysis. APM, and AB analyzed the data, and APM drafted the manuscript. All authors read and approved the final manuscript.

\section{Acknowledgements \\ This study was carried out at the Coimbra Nursing School, Coimbra, Portugal. We would like to extend our appreciation to Nigar G. Khawaja for granting the permissions to translate Multicultural Mental Health Awareness Scale-MMHAS and to use the Multicultural Mental Health Awareness Scale-MMHAS Portuguese version. The authors are very grateful to all the nurses who accepted to be part this study.}

Funding

No funding was obtained for this study.

\section{Author details}

${ }^{1}$ Coimbra Nursing School, Rua 5 de Outubro-Apartado 55, 3001-901 Coimbra, Portugal. ${ }^{2}$ Centro Hospitalar e Universitário de Coimbra (CHUC), Praceta Prof. Mota Pinto, 3000-075 Coimbra, Portugal. 
Received: 14 October 2015 Accepted: 4 May 2016

\section{Published online: 17 May 2016}

\section{References}

1. United Nations. Population division: replacement migration. In is it a solution to declining and ageing populations? New York: UN; 2000.

2. Health and Human Rights Info WEBSITE. 2014. Accessed 8 September 2015. Available in http://www.hhri.org/thematic/asylum_seekers.html.

3. Pumariega AJ, Rothe E, Pumariega JB. Mental health needs of immigrants and refugees. Community Ment Health J. 2005;41(5):581-97.

4. Monteiro AP. Migração e saúde mental, (migration and mental health) Viseu: PsicoSoma; 2011.

5. De Almeida Vieira Monteiro AP, Serra AV. Vulnerability to stress in migratory contexts: a study with eastern European immigrants residing in Portugal. J Immigr Minor Health. 2011;13(4):690-6. doi:10.1007/s10903-011-9451-z.

6. International Council of Nurses-ICN. Press release. 11 September 2015. Geneva, Switzerland. Accessed 28 Sept 2015. Available in: http://www.icn. ch/images/stories/documents/news/press_releases/2015_PR_24_Refugee_ Migrant healthcare.pdf.

7. Lehman D, Fenza PJ. The Shift towards Cultural Competency in the Nursing Care of Older Adults. An Orange Paper from Mather LifeWays, 2011. Accessed 1 Jul 2014. Available in: http://www.matherlifewaysinstituteonaging.com/wpcontent/uploads/2012/03/The-Shift-Towards-Cultural-Competency-in-theNursing-Care-of-Older-Adults.pdf.

8. Nardi D, Waite R, Killian P. Establishing standards for culturally competent mental health care. J Psychosoc Nurs Ment Health Serv. 2012;50(7):3-5. doi: 10.3928/02793695-20120608-01.

9. Geron SM. Cultural competency: How is it measured? does it make a difference? Generations. 2002;26(3):39-45.

10. Campinha-Bacote J. Cultural diversity in nursing education: issues and concerns. J Nurs Educ. 1998;37(1):3-4

11. Sue DW, Sue D. Counseling the culturally diverse: theory and practice. 4th ed. New York: Wiley; 2003.

12. Sue DW, Sue D. Counselling the culturally different: Theory and practice. 2nd ed. New York: John Wiley \& Sons; 1990.

13. Sue DW, Arredondo P, McDavis RJ. Multicultural counseling competencies and standards: a call to the profession. J Couns Dev. 1992;70:477-86.

14. Campinha-Bacote J. The process of cultural competence in the delivery of healthcare services: a model of care. J Transcult Nurs. 2002;13(3):181-4

15. Arredondo P, Toporek R, Brown SP, Jones J, Locke D, Sanchez J, et al. Operationalization of the multicultural counseling competencies. J Multicult Couns Dev. 1996;24:42-78.

16. Pinto-Meza A, Moneta MV, Alonso J, Angermeyer MC, Bruffaerts R, Caldas de Almeida JM, et al. Social inequalities in mental health: results from the EU contribution to the world mental health surveys initiative. Soc Psychiatry Psychiatr Epidemiol. 2013;48(2):173-81. doi:10.1007/s00127-012-0536-3. Epub 2012 Jul 18.

17. Monteiro AP. Migration integration and internationalization of health care: immigration, mental health of eastern European immigrants in Portugal, IMISCOE international migration. Lisbon: Integration and Social Cohesion Conference; 2008.

18. Freire JE, Moleiro C, Farcas D, Pereira C, Pinto N, Roberto S, et al. Avaliação de competências para a diversidade individual e cultural: desenvolvimento de uma medida comportamental para profissionais de saúde mental. In: Cruz F, Ribeiro J, editors. Migrações e interculturalidade. Porto: AGIR Associação para a Investigação e Desenvolvimento; 2010. p. 241-63. ISBN 978-989-8170-17-0

19. Monteiro AP, Mendes AC. Multicultural care in nursing - from the theoretical paradigm to the subjective experiences in clinical settings. Open J Nurs. 2013;3:557-62. doi:10.4236/ojn.2013.38076.

20. Loftin C, Hartin V, Branson M, Reyes H. Measures of Cultural Competence in Nurses: An Integrative Review. The Scientific World Journal 2013; 4: 289101. Retrieved March 27th, 2014 from http://dx.doi.org/10.1155/2013/289101.

21. Moleiro C, Marques S, Pacheco P. Cultural diversity competencies in child and youth care services in Portugal: development of two measures and a brief training program. Child Youth Serv Rev. 2011;33(5):767-73.

22. Khawaja NG, Gomez IF, Turner G. Development of the multicultural mental health awareness scale. Aust Psychol. 2008;44(2):1-11.

23. British Psychological Society Ethics Guidelines for Internet-mediated Research. Leicester: The British Psychological Society. 2003. Accessed 8 Jun 2013.
Available in: http://www.bps.org.uk/system/files/Public\%20files/inf206guidelines-for-internet-mediated-research.pdf.

24. APA. Ethical Principles of Psychologists and Code of Conduct. 2013. Accessed 8 Jun 2013. Available in: http://www.apa.org/ethics/code/.

25. Campinha-Bacote J. Delivering Patient-Centered Care in the Midst of a Cultural Conflict: The Role of Cultural Competence OJIN: The Online Journal of Issues in Nursing. 2011; 16 (2):5.DOl: 10.3912/OJIN.Vol16No02Man05.

26. Sue DW, Bernier JE, Durran A, Feinberg L, Pedersen P, Smith EJ, VasquezNuttall E. Position paper: Cross-cultural counseling competencies. Couns Psychol. 1982;10:45-52.

27. Nunnally JC, Bernstein IH. Psychometric theory. McGrawHill: New York, NY; 1994

28. Hill MM, Hill A. Investigação por questionário. Edições Sílabo: Lisboa; 2000.

29. George D, Mallery P. SPSS for windows step by step: a simple guide and reference. 11.0 update (4th ed.) Boston: Allyn \& Bacon; 2003.

30. Smith WG. Does Gender Influence Online Survey Participation?: A Record-linkage Analysis of University Faculty Online Survey Response Behavior. ERIC-Education Resources Information Center, 6 June 2008. Retrieved on Setember 28th, 2015 Available in: http://scholarworks.sjsu.edu/cgi/viewcontent. cgi?article $=1003 \&$ context=elementary_ed_pub.

\section{Submit your next manuscript to BioMed Central and we will help you at every step:}

- We accept pre-submission inquiries

- Our selector tool helps you to find the most relevant journal

- We provide round the clock customer support

- Convenient online submission

- Thorough peer review

- Inclusion in PubMed and all major indexing services

- Maximum visibility for your research

Submit your manuscript at www.biomedcentral.com/submit
) Biomed Central 